\author{
Military Technical College \\ Kobry El-Kobbah, \\ Cairo, Egypt
}

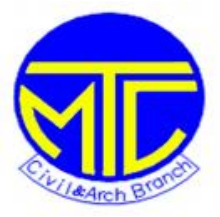

\title{
3-D Modeling of Pyramid Cover Systems to Retrofit Hexagonal Core Sandwich Structures
}

\author{
A. A. Mostafa ${ }^{1}$, A. H. Salem ${ }^{2}$, M. A. Wahab ${ }^{3}$, S. A. Mazek ${ }^{4}$
}

\begin{abstract}
Fortified structures are considered very important structures in military enginee ring fields due to a continuous development of conventional weapon. The fortified structures are constructed above or under ground. Blast wave causes structure damages based on explosive weight and distance between charge and target. Armoured doors are used in fortified structures in order to protect people, weapons, and ammunition from blast waves. Sandwich armoured steel door may be damaged as it is hit by blast waves. In the present study, the prediction of the sandwich armoure d steel doors performance under the impact of blast wave effect is highlighted. A 3-D numerical model is proposed to study pyramid cover system (PCS) layer to retrofit sandwich armoured steel doors using a 3-D nonlinear finite element analysis (FEA). Hexagonal core sandwich (XCS) doors are used so as to study blast mitigation using the PCS layer. Blast field test is implemented to understand performance of armoured XCS doors with and without the PCS. The study presents a comparison between the field blast test and the finite element analysis results to assess the accuracy of the proposed 3-D finite element model (FEM). The constitutive model for this analy sis contains elasto-plastic materials. An elasto-plastic model is employed to represent the armoured doors, the concrete wall of the fortified structure, and the PCS layer. The proposed model is programmed and linked to an available computer program Auto dyn3D (2005).

The 3-D nonlinear FEM takes into account the effects of the blast load, the connection between the armoured doors and the frame fixed to the concrete wall, and the PCS layer. The effects are expressed in terms of displacement -time history of the sandwich armoured doors and pressure-time history on armoured XCS doors as the explosive wave propagates. The behavior of the sandwich armoured XCS doors sheltered by the PCS is investigated and presented under blast waves obt ained from detonating 1-kg, 2$\mathrm{kg}$, and 3-kg TNT explosive charge at a scaled distance of $1 \mathrm{~m}$.
\end{abstract}

\section{Keywords}

Displacements, finite element analysis, blast wave, sandwich structures, armoured doors.

\footnotetext{
${ }^{1} \mathrm{Ph}$. D. Egyptian Engineering Military Department.

${ }^{2}$ Professor, Structural Engineering Department, Faculty of Engineering, Ain Shams University, Cairo.

${ }^{3}$ President of Technical Research Department, Cairo, Egypt.

${ }^{4}$ Associate Professor, Civil Engineering Department, Military Technical College, Cairo, Egypt.
} 


\section{Introduction}

Technologies provide blast protection for both military and civilian structures (Aimone, 1982; Liu and Katsabanis, 1997; Fayad, 2009; Mohamad, 2006; Schueller, 1991; Zhang and Valliappan, 1990). In order to develop protection technologies, there is a need to understand both dynamic interaction of blast loading with structures an d shock mitigating mechanisms. Traditional lightweight materials such as foam and honeycomb core system are effective for blast protection applications because of their ability to mitigate shock blast wave transferred to structures (Gustafsson, 1973; Liu and Katsabanis, 1997; Technical Manual TM 5-885-1, 1986; Technical Manual TM 5-1300, 2008).

Composite structures are used in many applications such as aircraft, automobile, and naval structures. Aircraft skeleton, interior panels, sport equipments, vehicl e skeleton, naval vessels, and medical equipment are examples of composite structures (Dharmasena et al., 2007; Ming, 2008). To better understand structural damage under dynamic conditions, there are many researches to study aerospace, naval, automotive, and defence-related structures (Beshara, 1994; Fayad, 2009; Laine and Hedman, 1999; Mohamad, 2006; Smith and Hetherington, 1994). The composite structures become an engineering challenge to understand performance of composite structure against blast effect.

In the present study, the performance of the armoured steel doors with internal hexagonal core structure systems (XCS) sheltered by pyramid cover system (PCS) under the impact of the blast wave effect is highlighted. The PCS is made of normal mild steel. The steel sheet thickness of the PCS is equal to $1 \mathrm{~mm}$ in this study. The 3-D model is proposed using finite element analysis (FEA) to study pyramid cover system to retrofit the sandwich armoured steel doors, as shown in Fig. 1. Hexagonal core sandwich door is used to study blast mitigation based on constant sheet thicknesses of the PCS. Field blast test is conducted in this study. The study presents a comparison between the field blast test and the finite element analysis to understand the impact of the pyramid cover system on the armoured steel door performance. The constitutive model for this analysis contains elasto-plastic materials. A modified Drucker-Prager model is used to model the rock media. An elasto-plastic model is also employed to represent the armoured doors, the concrete wall of the structure performance, and the PCS layer. The armoured door model with and without the PCS is implemented in a finite element code Autodyn 3D (2005).

Current codes and regulations to estim ate blast wave intensities due to outdoor blasting at the entrance of fortified structures are used in the present study based on empirical methods (Gustafsson, 1973; Technical Manual TM 5-885-1, 1986; Technical Manual TM 5-1300, 2008). These empirical methods were obtained from observations and measurements in field blast tests. The empirical methods tended to overlook the physical laws governing the proc ess in blasting effect.

The finite element model takes into account the effects of the blast load, the connectio $n$ between the armoured XCS door and the frame fixed to the concrete wall, and the pyramid cover system. The effects are expressed in terms of the displacement-time history of the sandwich armoured doors as the explosive wave propagates. A parametric study based on the 3-D nonlinear finite element analysis is conducted to study the impact of the PCS on the sandwich armoured steel door performance based on different TNT charges. The behavior of the sandwich armoured door is investigated 
under the blast waves obtained from detonating 1-kg, 2-kg, and 3-kg TNT explosive material at a scaled distance of $1 \mathrm{~m}$.

Numerical results obtained by the finite element analysis are compared with the data obtained from the field test. The numerical model can well predict the blasting-induced pressure on the armoured doors. Displacement-time history of armoured XCS door using the PCS is computed and presented.

\section{Blast Field Test}

Field blast tests are conducted to understand the XSC door performance at the entrance of fortified structures based on different explosive charges and the PCS. Two models of armoured door with internal hexagonal core system are prepared and used. The first steel door model without the PCS is tested and subjected to $1-\mathrm{kg}, 2-\mathrm{kg}$, and 3-kg TNT charges, as shown in Fig. 2. The sheet steel plate is normal mild steel sheet. The internal spacing between the two steel sheet plates is $10 \mathrm{~cm}$. Each steel sheet is $1.0 \mathrm{~m}$ long, $1.0 \mathrm{~m}$ width, and $3 \mathrm{~mm}$ thick. The dimensions of the hexagonal core system are $7.8 \mathrm{~cm}$ long and $1 \mathrm{~mm}$ thick, as shown in Fig. 2. The internal core structure system is assumed to improve armoured door performance against blast effect. The second steel door model is sheltered by the PCS. The second door model is also tested and subjected to $1-\mathrm{kg}$ TNT, 2-kg TNT, 3-kg TNT, as shown in Fig. 3. The length of the pyramid base is $20 \mathrm{~cm}$ and its height is $10 \mathrm{~cm}$. The thickness of the steel sheet for the pyramid stiffener is $1 \mathrm{~mm}$.

The previous specimens are prepared and assembled with special requirements to be tested against TNT explosives. A test rig is prepared and used to simulate armoured door boundary in free air. However, the test rig also nee ds some precautions to satisfy boundary conditions for free air explosion. The dimension of the test rig is $2 \mathrm{~m} \mathrm{x} 2 \mathrm{~m} \mathrm{x}$ $2 \mathrm{~m}$, as shown in Fig. 4. The members of the test rig are box sections composed from two channel $140 \mathrm{~mm}$ each. These box members are welded face to face. Angles (70 $\mathrm{mm} \times 7 \mathrm{~m}$ ) are also welded to the box members in vertical and horiz ontal directions so as to support the test models. The height of the supporting angles is $1.0 \mathrm{~m}$ and their width is $1.0 \mathrm{~m}$, as shown in Fig. 4 .

The sensor interface PCD-30A is a voltagemeter that is connected with the personal computer so as to record pres sure-time history due to blast effect. This device is capable of measuring voltage which is recorded and attached to control software. This system can measure four channels. Fig. 5 shows the field instrumentation devices .

The hexagonal core system (XCS) is subjected to blast waves obtained from 2-kg TNT explosive charge, as shown in Fig. 6.

\section{Finite Element Model of Hexagonal Core Sandwich Structure}

In numerical modeling, air and equivalent explosive TNT are simulated by Euler processor, as shown in Fig. 7. The air and the equivalent explosive TNT are assumed to satisfy the equation of state (EOS) of ideal gas (Hao et al. 1998). Rock media, reinforced concrete wall (RC) of the fortified structure, and the PCS are modeled by the modified isotropic damage model and simulated by Lagrange process or (Hao et al. 1998, Wu et al. 1999), as shown in Fig. 7. The whole domain, including the rock media, the air media, the RC wall, the PCS, the armoured XCS door, and TNT explosive, is shown in Fig. 8. Transmitting boundary is used to reduce reflection of 
stress wave from the numerical boundaries. The material constants of the rock mass obtained from site investigation are used in numerical simulation, whi le standard constants of air, TNT, and the PCS are obtained from the Autodyn3D material library. These include Poisson's ratio of the rock media $v=0.16$; averaged mass density of rock media $2600 \mathrm{~kg} / \mathrm{m}^{3}$; yield strength of rock $\mathrm{f}_{\mathrm{y}}=390 \mathrm{~kg} / \mathrm{cm}^{2}$; bulk modulus of rock $E_{i}=260 \mathrm{t} / \mathrm{cm}^{2}$; air mass density $\rho=1.225 \mathrm{~kg} / \mathrm{m}^{3}$; air initial internal energy $E_{n}=2.068 \times 10^{5} \mathrm{~kJ} / \mathrm{kg}$; and ideal air constant $\gamma=1.4$. The shear modulus of the rock mass depends on the elastic modulus $E_{i}$ and Poisson's ratiov. It should also be noted that viscous damping effect is neglected in the numerical simulation as its influence on high velocity explosion-type responses is insignificant (Hao et al., 1998; Wu et al., 1999).

Shell element is used to model both the membrane (in-plane) and the bending (out-ofplane) behavior of the armoured doors including the internal hexagonal core structure system and the PCS, as shown in Figs. 1, 7, and 8. The boundary condition applied to the armoured door is defined from tow latches and tow hinges, as shown in Fig. 9. The dimensions of the armoured door are also shown in Fig. 9. A 4-node rectangular shell element is used for modeling the armoured door with each node having 6 degrees of freedom (three translations and three rotations).

The solid element is also used to model the behavior of the rock media and the concrete structure. The solid element is chosen since it possesses in -plane and out-of-plane stiffnesses. The solid element allows for both in-plane and out-of-plane loads. The solid element is cubic in shape and has 8 nodes each having 3 degrees of freedom (three translations).

The mechanical properties of concrete are: Poisson's ratiov $=0.18$; averaged mass density $2520 \mathrm{~kg} / \mathrm{m}^{3}$; elastic modulus $\mathrm{E}=220 \mathrm{t} / \mathrm{cm}^{2}$; compressive strength $\mathrm{f}_{\mathrm{n}}=500$ $\mathrm{kg} / \mathrm{cm}^{2}$; and strain at failure $\varepsilon_{\mathrm{f}}=0.001$. The shear modulus of the concrete mass depends on the elastic modulus E and Poisson's ratio $v$.

The mechanical properties of the steel door and the PCS are: Poisson's ratiov $=0.3$; averaged mass density $7900 \mathrm{~kg} / \mathrm{m}^{3}$; elastic modulus $E=2100 \mathrm{t} / \mathrm{cm}^{2}$; and yield strength $\mathrm{f}_{\mathrm{y}}=2400 \mathrm{~kg} / \mathrm{cm}^{2}$. The shear modulus of the steel depends on the elastic modulus $\mathrm{E}$ and Poisson's ratiov .

The cubic solid element and the rectan gular shell element interface is used between the rock media, the concrete walls of the structure, the PCS, and the armoured door to ensure the compatibility conditions at the interface surface between them as well as the associated stresses and strains along the interface surface. This type of finite element is used to link adjacent nodes characterized by stiffness components.

\section{Analysis of the Mathematical Model}

The shock of the blast wave is generated when the surrounding atmosphere is subjected to an extreme compressive pulse radiating outward from the centre of the explosion. The pressure-time history of a blast wave can be illustrated with a general sha pe, as shown in Fig. 10 (Gaissmaire, 2003). The illustration is an idealization for an explosion in free air. Transient pressure being greater than ambient pressure is defined as the overpressure $\left(P_{s}\right)$ (Smith and Hetherington, 1994). The peak overpressure $\left(P_{s}\right)$ is the maximum value of the overpressure at a given location. The rise time to peak overpressure is less than microsecond (Baker et al., 1983). 
The study presents a comparison between the pressure-time history obtained by the empirical method (EM) developed by Henrych (Beshara, 1994), by the field blast test, and by the finite element analysis (FEA). The EM method uses the scaled distance (Z) equation (1) to calculate the peak overpressure (Beshara, 1994).

$$
Z=\frac{R}{\sqrt[3]{W}}
$$

Where; $\mathrm{R}$ is the distance from the centre of the explosion to a given location in meter and $\mathrm{W}$ is the weight of the explosive in $\mathrm{kg}$.

The equations developed by Henrych (Beshara, 1994) divide the analysis into three fields based on one-meter scaled distances $(Z)$ as presented in equations 2 to 4 .

$$
\begin{array}{ll}
P_{s}=\frac{14.072}{Z}+\frac{5.540}{Z^{2}}-\frac{0.357}{Z^{3}}+\frac{0.00625}{Z^{4}}(\text { bar) } & (\text { for } 0.05<\mathrm{Z}<0.3) \\
P_{s}=\frac{6.194}{Z}-\frac{0.326}{Z^{2}}+\frac{2.132}{Z^{3}}(\text { bar }) & (\text { for } 0.3<\mathrm{Z}<1) \\
P_{s}=\frac{0.662}{Z}+\frac{4.05}{Z^{2}}+\frac{3.288}{Z^{3}}(\text { bar }) & (\text { for } 1<\mathrm{Z}<10)
\end{array}
$$

The scaled distance $(\mathrm{Z})$ is also used to determine the positive duration time $\left(\mathrm{T}_{\mathrm{s}}\right)$ and the positive impulse $\left(i_{\mathrm{s}}\right)$ by using Fig. 11 (Smith and Hetherington, 1994).

The study is also extended to assess the accuracy of the proposed finite e lement model. One-kg TNT, two-kg TNT, and three-kg TNT are applied at scaled distance of one meter to obtain the pressure-time history hitting the armoured door by the EM, the FEA, and the field blast test at points 1 and 2 (Fig. 9), as shown in Figs. 12 to 14. The result shows that the readings obtained by the field blast test agree well with those estimated by the FEA and the EM. The trend of the pressure-time history hitting the armoured door obtained by both the field measurements and the FEA is the same trend presented by Gaissmaire (2003), as shown in Figs. 10, 12, 13, and 14.

\section{Impact of Blast Load on XCS Door Pe rformance with and without PCS}

The displacement-time history of the armoured door with hexagonal core sandwich (XCS) due to blast load is calculated using the proposed finite element model. The blast load affects the entrance of the fortified structure. The finite element model is also used to calculate the displacement-time history of the armoured XCS door with the PCS as mitigation system. The study discusses the impact of the PCS layer on the armoured door performance under the blast impact.

Two cases of the armoured XCS door with and without the PCS layer are studied at the entrance of the fortified structure. For the first case, the XCS door is modeled without using the PCS layer. For the second case, the XCS door is modeled using the PCS layer.

One-kg TNT explosive is used to discuss the impact of the PCS layer on the armoured doors with hexagonal core sandwich (XCS) at points 1 and 2 (Fig. 9). The TNT explosive is located at the entrance of the fortified structure within one-meter scaled 
distance, as shown in Fig. 8. The pressure- time history hitting the armoured door is presented in Fig. 12. Figure 15 shows the comparison between the displacement-time history results at point 1 for each case. Figure 16 presents the comparison between the displacement-time history results at point 2 for each case. The comparison indicates that the deformation of the armoured XCS door covered by the PCS layer is smaller than that of the armoured XCS door without the PCS layer.

Two-kg TNT explosive is also used to discuss the impact of the PCS layer on the armoured XCS door at points 1 and 2. The pressure- time history hitting the armoured door is presented in Fig. 13. Figure 17 shows the comparison between the displacement-time history results at point 1 for each case. Figure 18 presents the comparison between the displacement -time history results at point 2 for each case. The comparison shows that the deformation of the armoured XCS door with the PCS layer is smaller than that of the armoured XCS door without the PCS layer.

Three-kg TNT explosive is again used to discuss the impact of the PCS layer on the armoured XCS doors at points 1 and 2. The results also show that the response of the armoured XCS door covered by the PCS layer is again smaller than the response of the armoured XCS door without the PCS layer, as shown in Figs. 19 and 20.

The difference between the performance of the armoured XCS doors with and without the PCS layer lies in the use of the PCS layer. The finite element analysis gives a better estimation of the response of the armoured door with and without the PCS layer based on the field blast test. In general, the armoured door plays an important role to resist the blast load. The case of the armoured door with the PCS layer gives the smallest displacement readings. Therefore, the PCS layer increases the armoured door stiffness and then reduces the deformation of the armoured door compared to the armoured door without the PCS layer. Finally, the performance of the armoured doors is highly dependent on the sheltered layer as the PCS layer which is used as a mitigation system.

\section{Conclusions}

A field blast test is conducted and implemented to study the performance of the XCS door with and without the PCS layer. A 3-D nonlinear finite element analysis is also used to predict the performance of armoured steel XCS doors with and without the PCS layers under the blast effect. The following conclusions can be drawn regarding the performance of the armoured XCS door with and without the PCS layer under the impact of explosives at the entrance of the fortified structure.

- The blast field test is implemented to understand the performance of armoured XCS doors with and without the PCS under the blast effect.

- Based on the field blast tests and the empirical method developed by Henrych, the 3-D finite element analysis gives a better estimate of the pressure-time history hitting the armoured steel door.

- The pressure-time history calculated by the finite element analysis is in reasonable agreement with that obtained by the empirical method developed by Henrych (Beshara, 1994).

- The 3-D finite element model can be successfully used to analyze and estimat e the performance of steel armoured doors with and without PCS layer.

- The pressure-time history profile of the armoured door calculated by the 3-D finite element analysis has the same trend as that obtained by the field blast test and that presented by Gaissmaire (2003). 
- Based on the present study, the PCS layer is used as sheltered layer to protect the armoured steel door against the blast wave propagation. The PCS layer reduces the maximum displacement of the armoured door by up to $60 \%$.

\section{References}

- Aimone, C. T. 1982. Three-Dimensional Wave Propagation Model of Full-Scale Rock Fragmentation. Ph.D. Thesis, Northwestern University.

- AUTODYN, "Theory Manuals", Version 6.1, Century Dynamics Inc., Sam Ramon, USA, 2005.

- Baker, W. E., Cox, P. A., Kulesz, J. J. and Strehlow, R. A. 1983. Explosion Hazards and Evaluation, Elsevier.

- Beshara, F.B.A. 1994. Modeling of blast loading on aboveground structures -I. Internal blast and ground shock, Comp. \& Structure Vol. 51, No.5.

- Dharmasena K. P., Wadley Hng, Xue Z, Hutchinson J. W. 2007. "Mechanical response of metallic honeycomb sandwich panels to high intensity dynamic loading. Int. J Impact Eng, 2007.

- Fayad, H. M. 2009. The Optimum Design of the Tunnels Armoured Doors under Blast Effects. Ph. D. Thesis. Military Technical College (MTC). Cairo

- Gaissmaiere, A. E. W. 2003. Aspects of thermobaric weapon. ADF Health, Vol. 4, pp. 3-6.

- Gustafsson, R. 1973. Swedish Blasting Technique. Gothenburg, Sweden, SPI.

- Hao, H., Ma, G. W. and Zhou, Y. X. 1998. Numerical Simulation of Underground Explosions. Fragblast the Int. J. of Blasting and Fragmentation, 2, pp. 383-395.

- Dharmasena K. P., Wadley H. N., Xue Z., John W. Hutchinson J. W. 2008. Mechanical response of metallic honeycomb sandwich panel structures to high -intensity dynamic loading International Journal of Impact Engineering 35 (2008) 1063-1074.

- Laine, L., and Hedman, O.1999. Finite Element Calculation of Swedish Rescue Centers (RC 90) and Shelters. $3^{\text {rd }}$ Asia-Pacific Conference on Shock \& Impact Loads on Structures, pp.205-212, November24-26, Singapore.

- Liu, L. and Katsabanis, P. D. 1997. Development of a Continuum Damage Model for Blasting Analysis. Int. J. Rock Mech. Min. Sci., 34, pp. 217-231.

- Ming Wei Hsieh. 2008. Investigation on the Blast Resistance of a Stiffened Door Structure" Journal of Marine Science and Technolo gy, Vol. 16, No. 2, pp. 149-157.

- Mohamad, L. S. 2006. Study and design of fortified structures due to blast effects. M. Sc thesis. Military Technical College (MTC). Cairo. Ammunition and Explosives. In document: AC/258-D/258, Brussels, Belgium.

- Technical Manual TM 5-885-1. 1986. Fundamentals of Protective Design for Conventional Weapons. Headquarters Department of the Army, Washington DC.

- Technical Manual TM 5-1300. 2008. Structures to Resist the Effects of Accidental Explotions. Unified Facilitie s Criteria (UFC) .U.S. Army Corps of Engineers; Naval Facilities Engineering Command; Air Force Civil Engineer Support Agency

- Schueller, C. T. 1991. Structural Dynamics. Springer-Verlag, Berlin, New York, ISBN 0-387-53593-4.

- Smith P. D. \& Hetherington J.G. 1994. Blast and ballistic loading of structures . Butterworth-Heinemann Ltd. UK. 
- Wu, C., Hao, H. and Zhou, Y. X. 1999. Dynamic Response Analysis of Rock Mass with Stochastic Properties Subjected to Explosive Loads. Fragblast the International J. Blasting and Fragmentation, 3, pp. 137-153.

- Zhang, W. and Valliappan, S. 1990. Analysis of Random Anisotropic Damage Mechanics Problems of Rock Mass, Part II: Statistical Estimation. Rock Mechanics and Rock Engineering, 23, pp. 241-259.
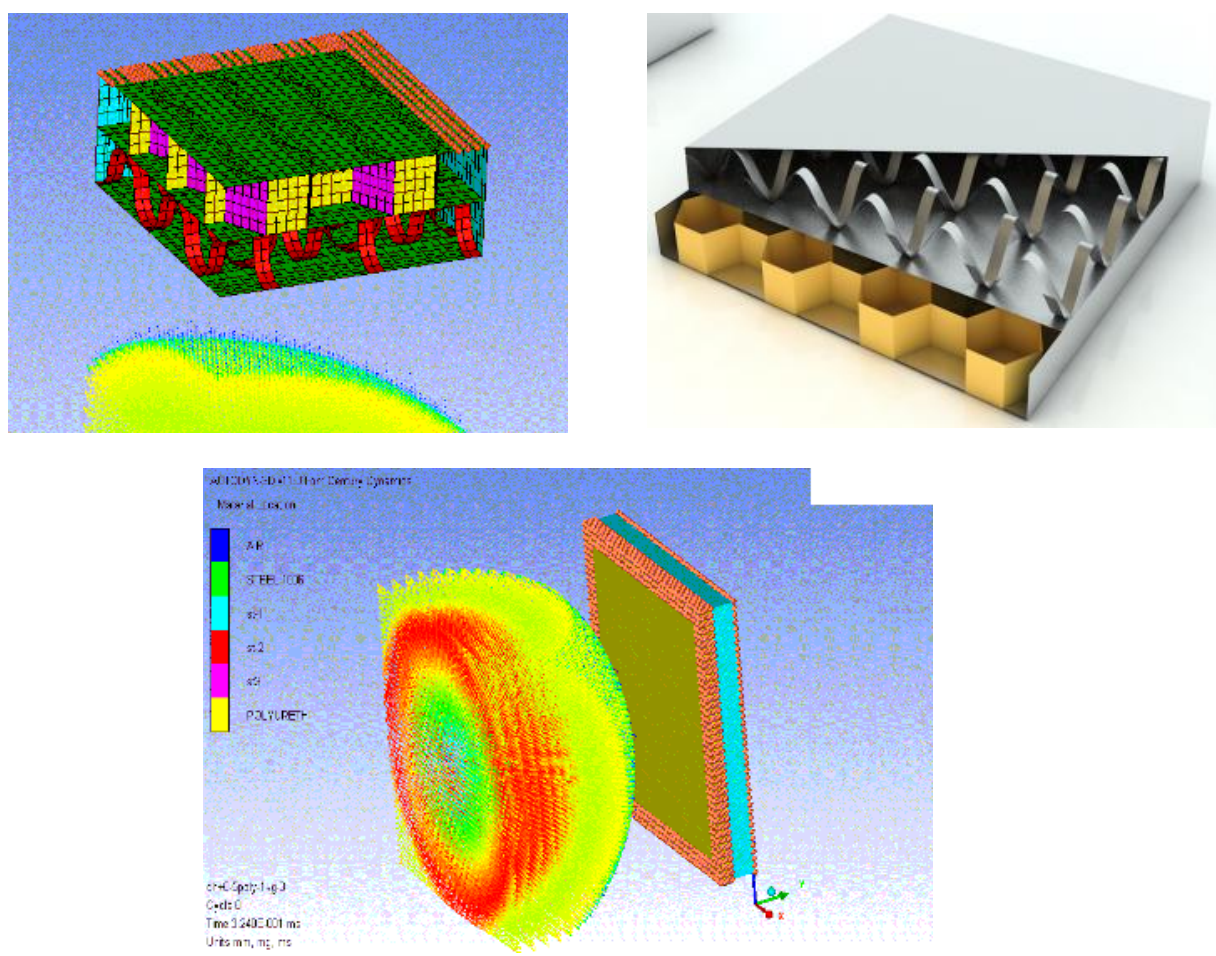

Fig. 1: Blast wave propagation hitting armoured sandwich door sheltered by PCS layer 


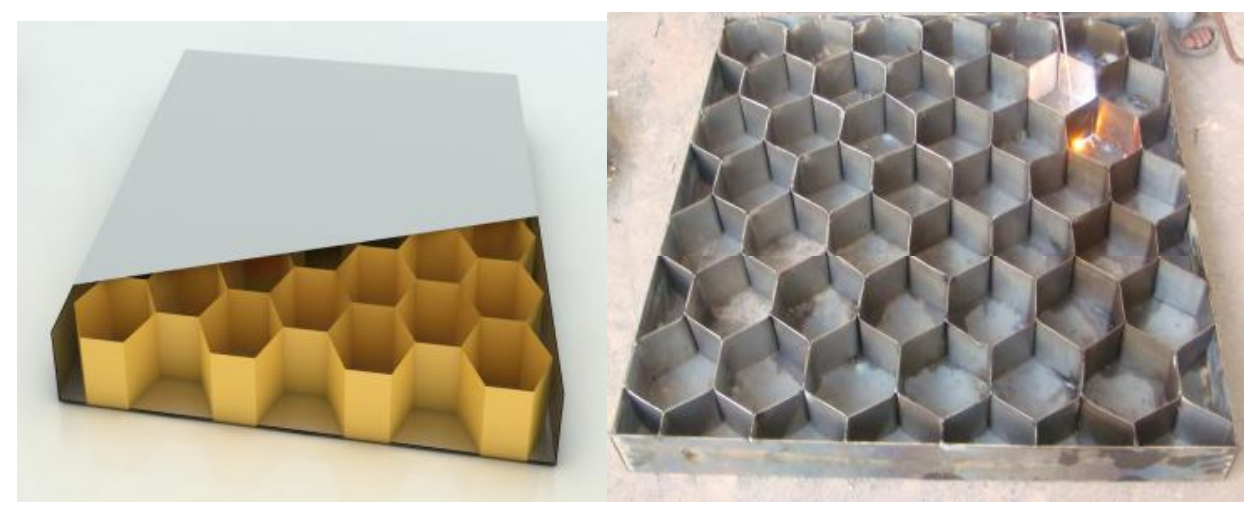

Hexagonal core sandwich door (XCS) (hexagonal tube)

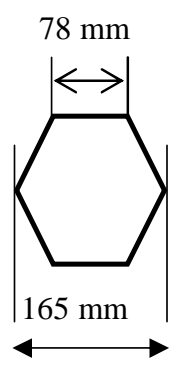

Cross section on each hexagonal tube (1 mm thickness)

Fig. 2: Hexagonal core sandwich door (XCS)
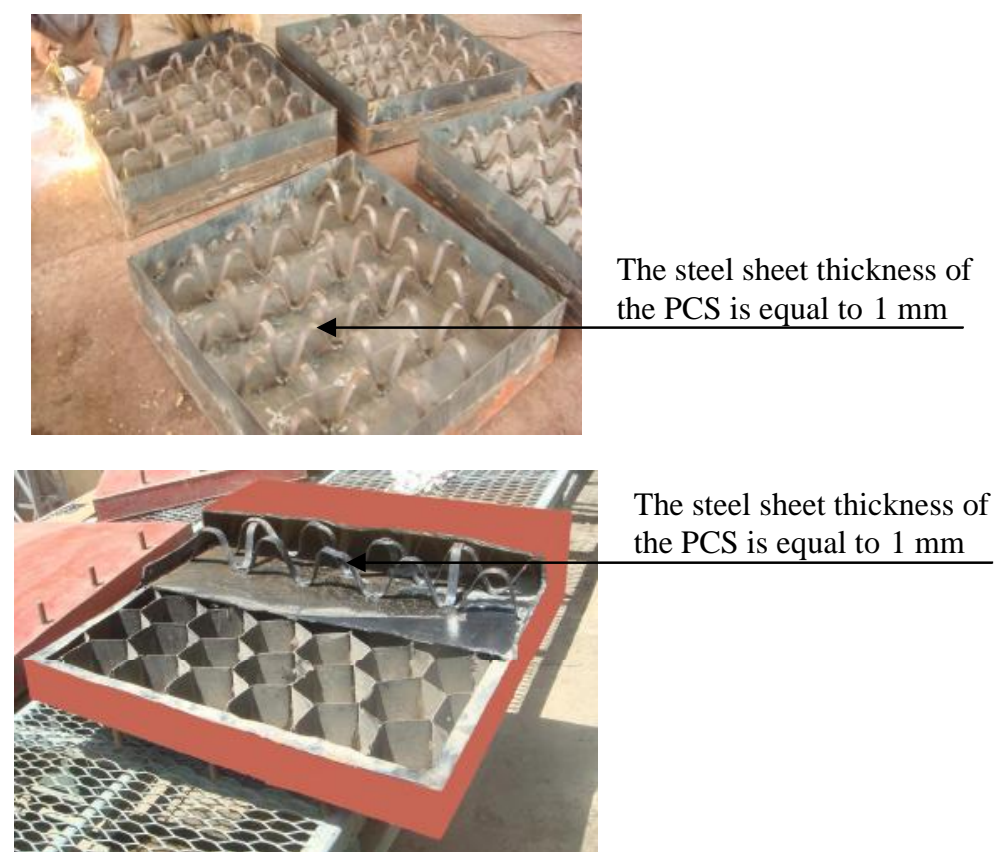

Fig. 3: Hexagonal core sandwich door (XCS) 


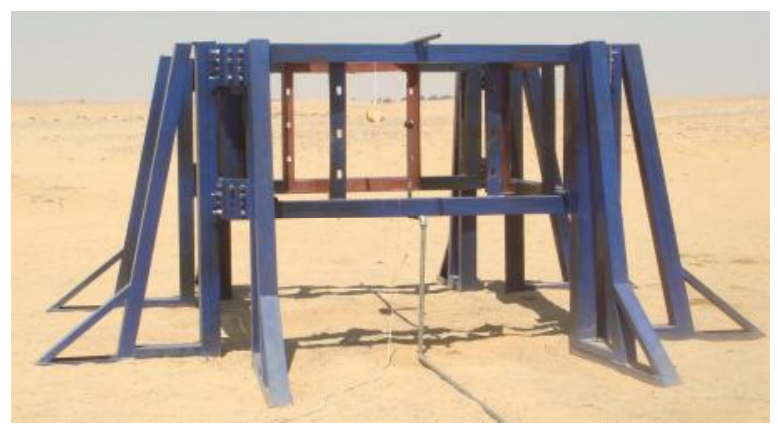

Fig. 4: Test rig

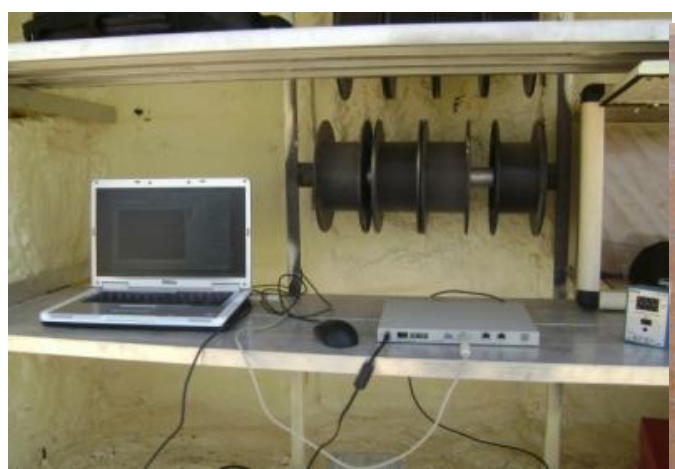

Field instrumentation devices

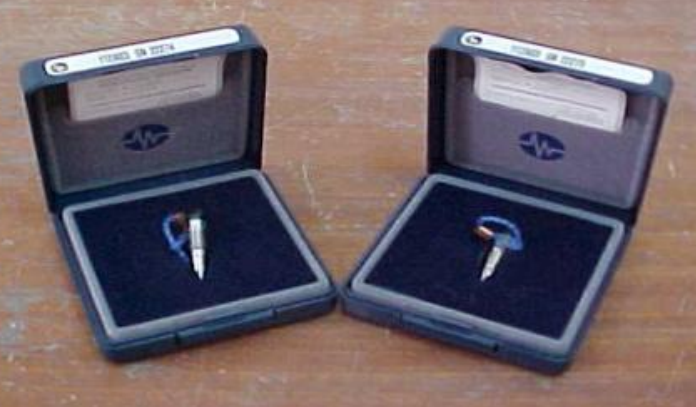

Pressure Sensors

Fig. 5: Field blast system measurement devices
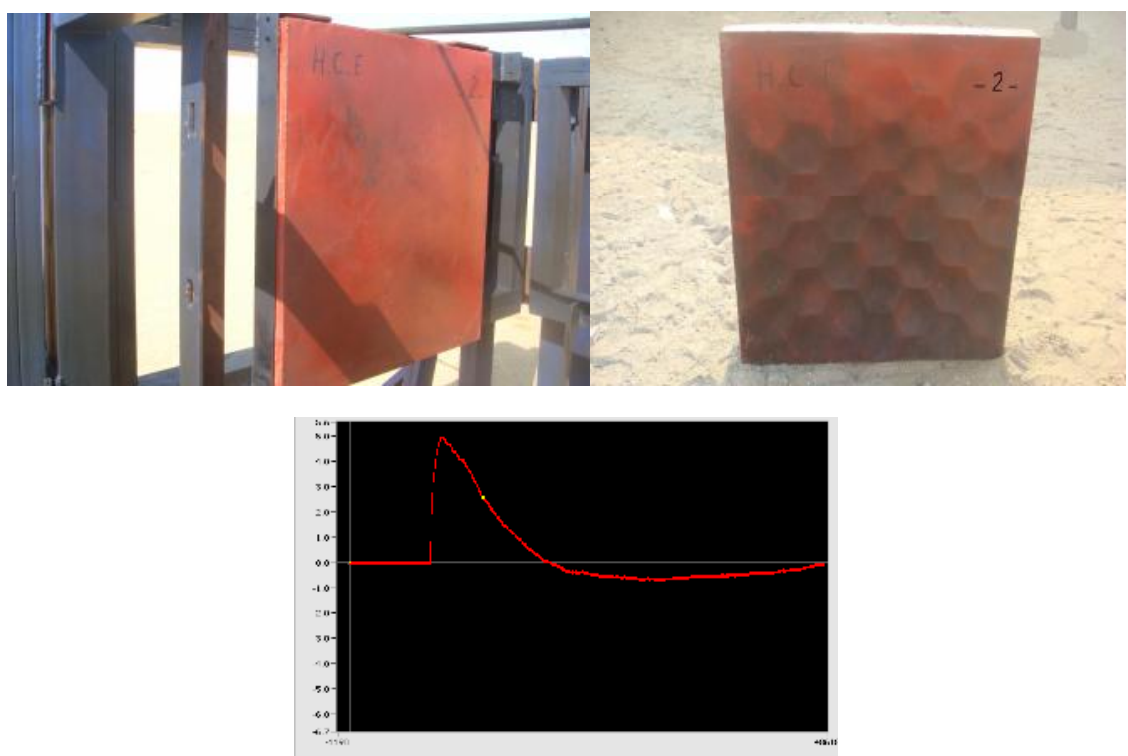

Fig. 6: Hexagonal core system (XCS) subjected to 2-kg TNT explosive charge 


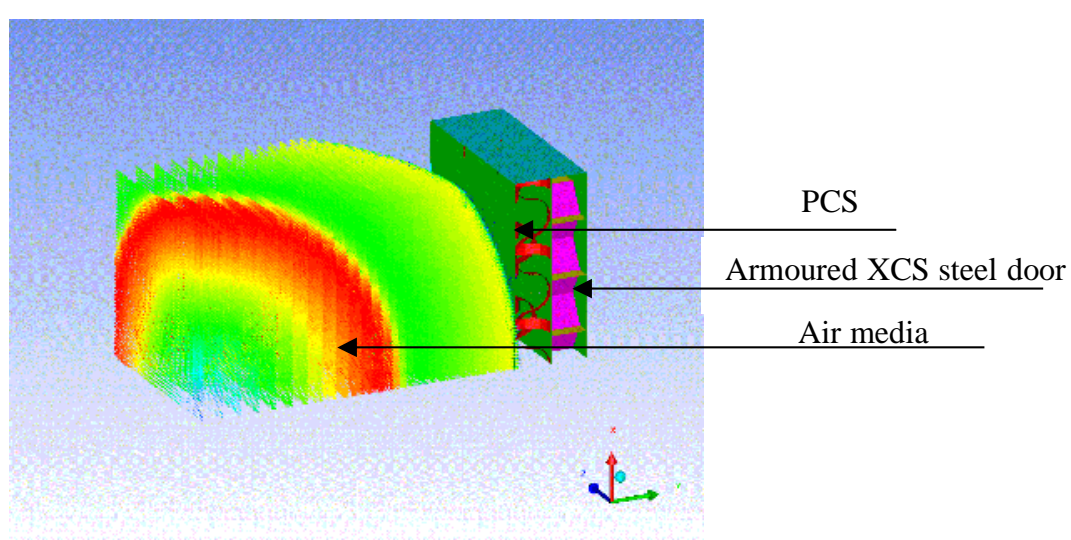

Fig. 7: 3-D finite element model of armoured XCS door with PCS layer

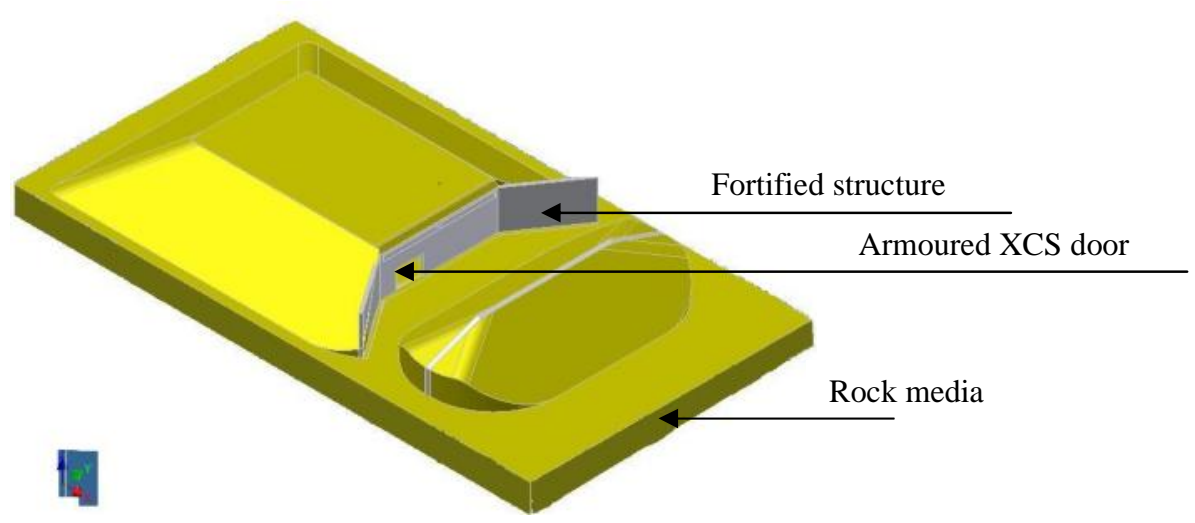

Fig. 8: Numerical model showing section elevation of RC wall, rock media, and steel armoured door

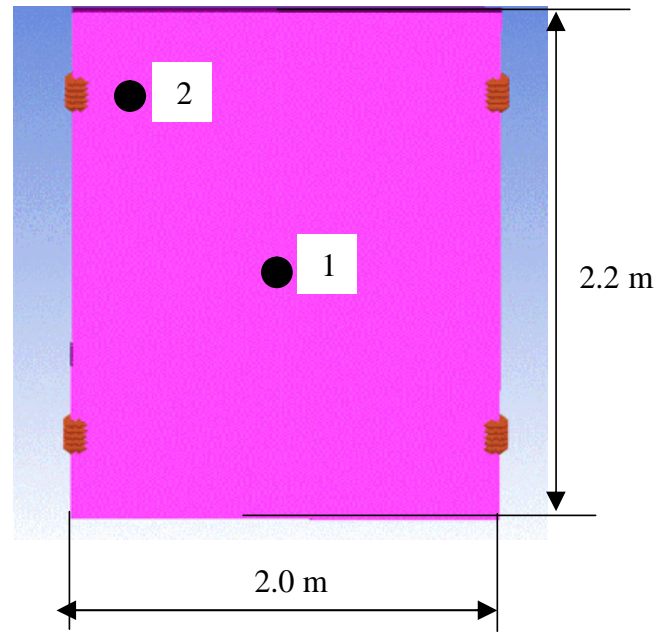

Fig. 9: Numerical model show ing the boundary condition of door and location of points 1 and 2 


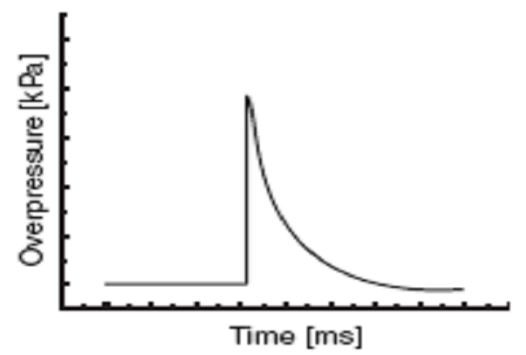

Fig. 10: Typical pressure time history in open air (Gaissmaire, 2003)

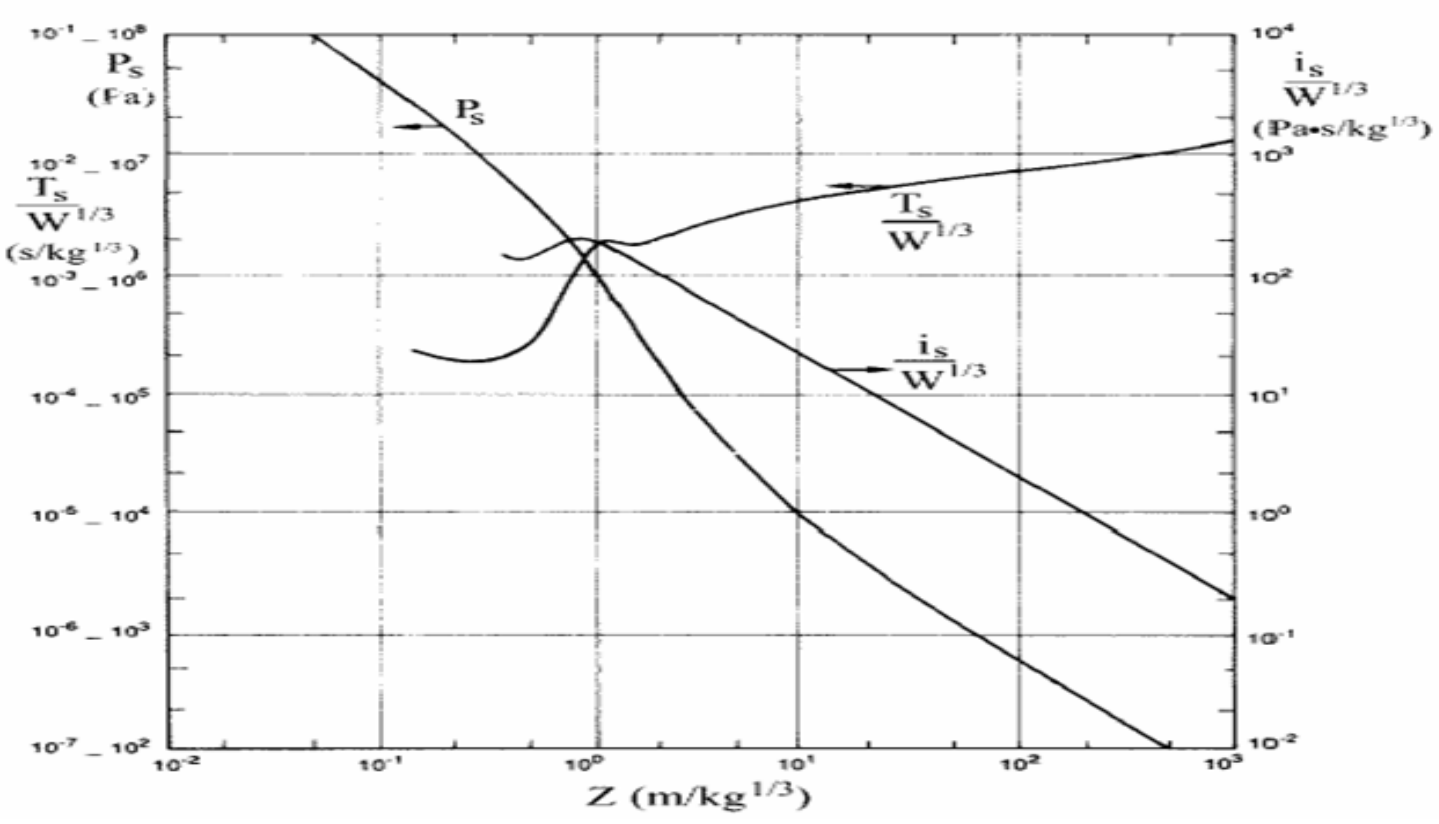

Fig. 11: Blast wave parameters for spherical charges of TNT ( Smith and Hetherington, 1994)

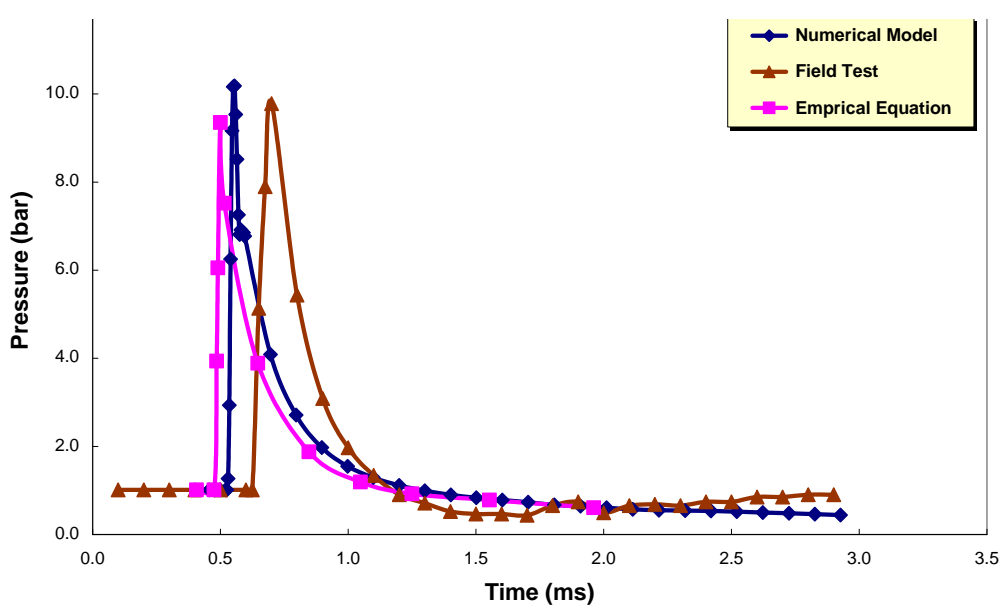

Fig. 12: Pressure-time history at point 1 based on 1-kg TNT explosive 


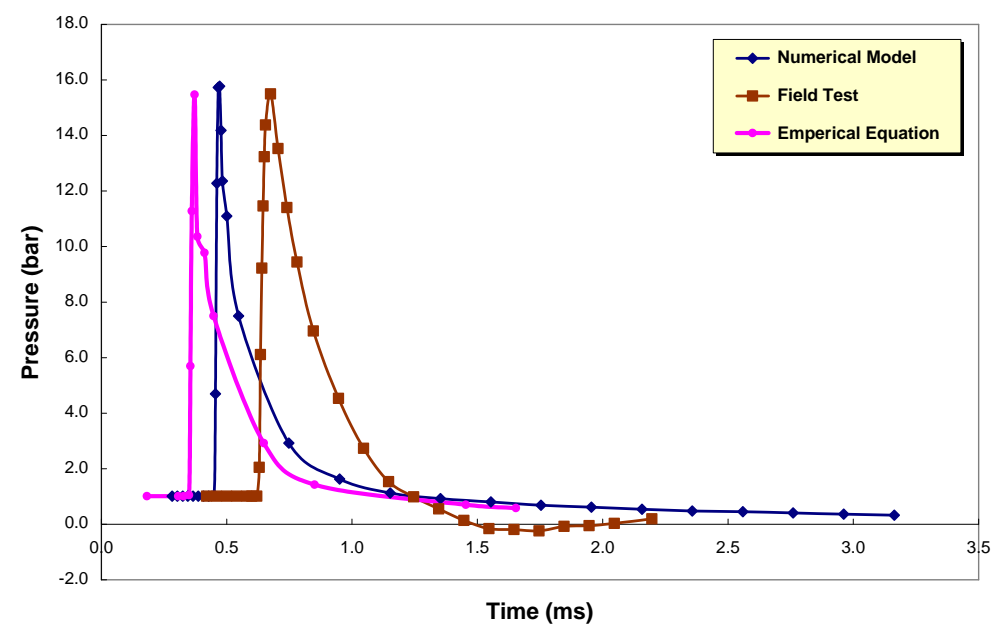

Fig. 13: Pressure-time history at point 1 based on 2-kg TNT explosive

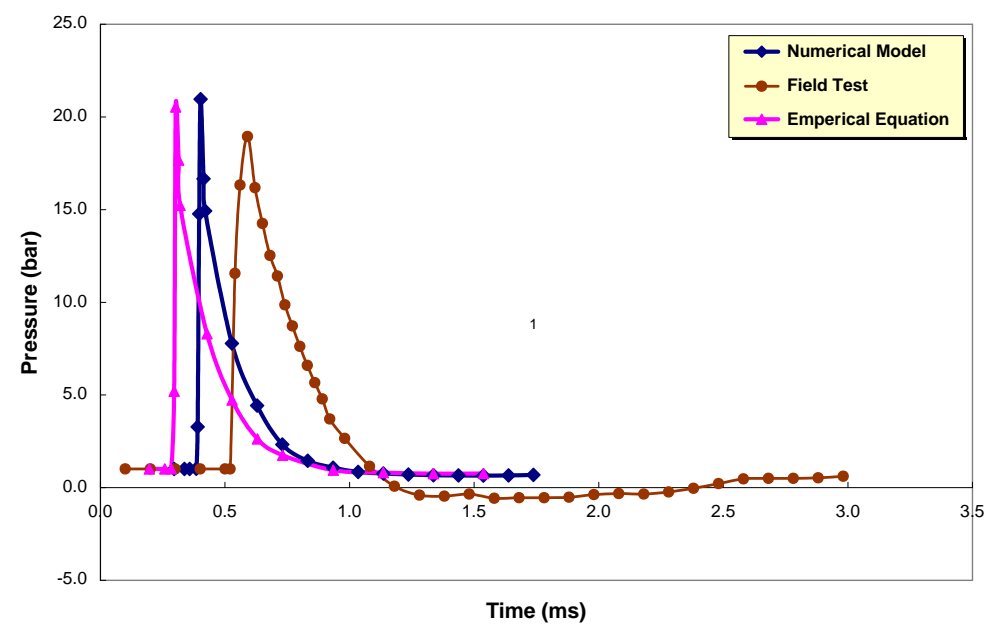

Fig. 14: Pressure-time history at point 1 based on 3-kg TNT explosive

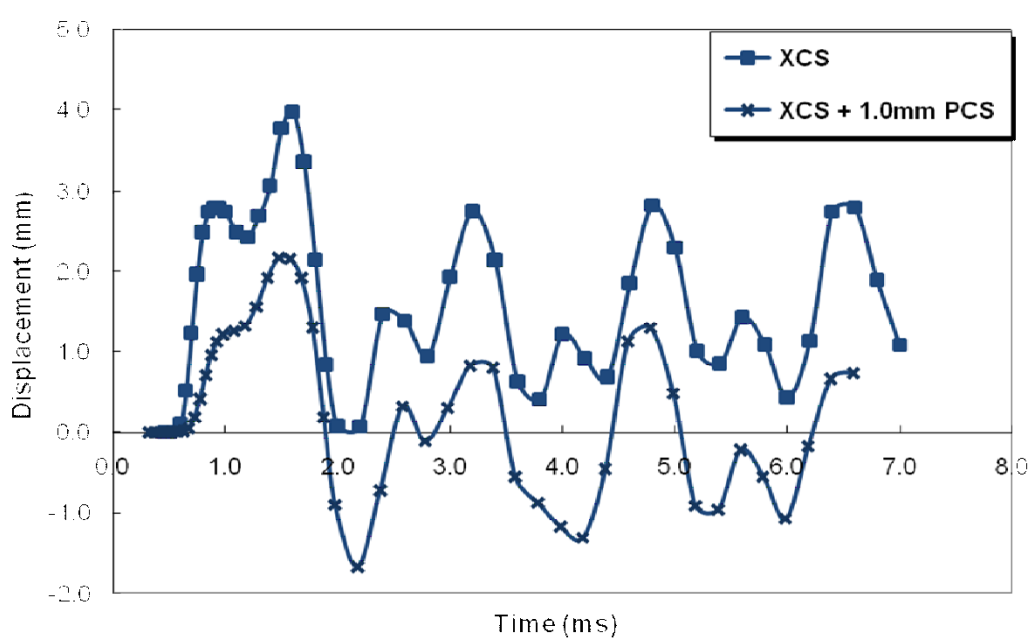

Fig. 15: Displacement-time history at point (1) of armoured XCS door for two cases (1 kg TNT) 


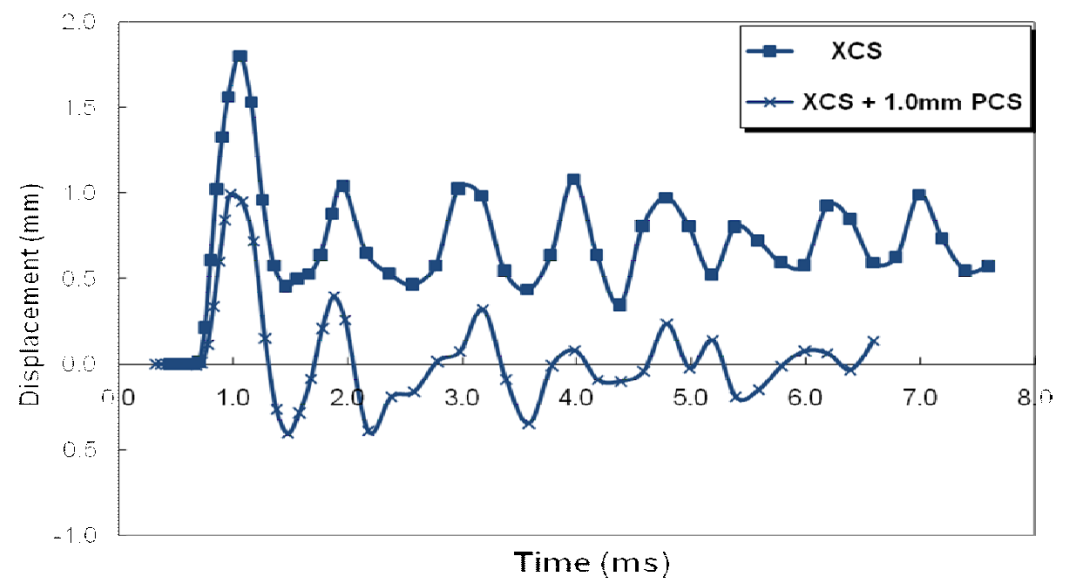

Fig. 16: Displacement-time history at point (2) of armoured XCS door for two cases (1 kg TNT)

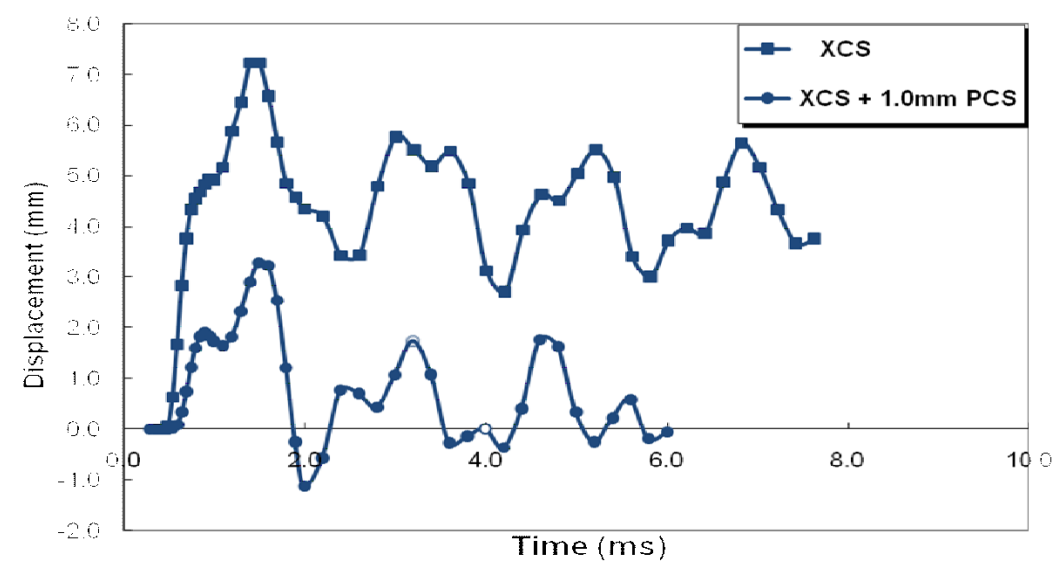

Fig. 17: Displacement-time history at point (1) of armoured XCS door for two cases (2 kg TNT)

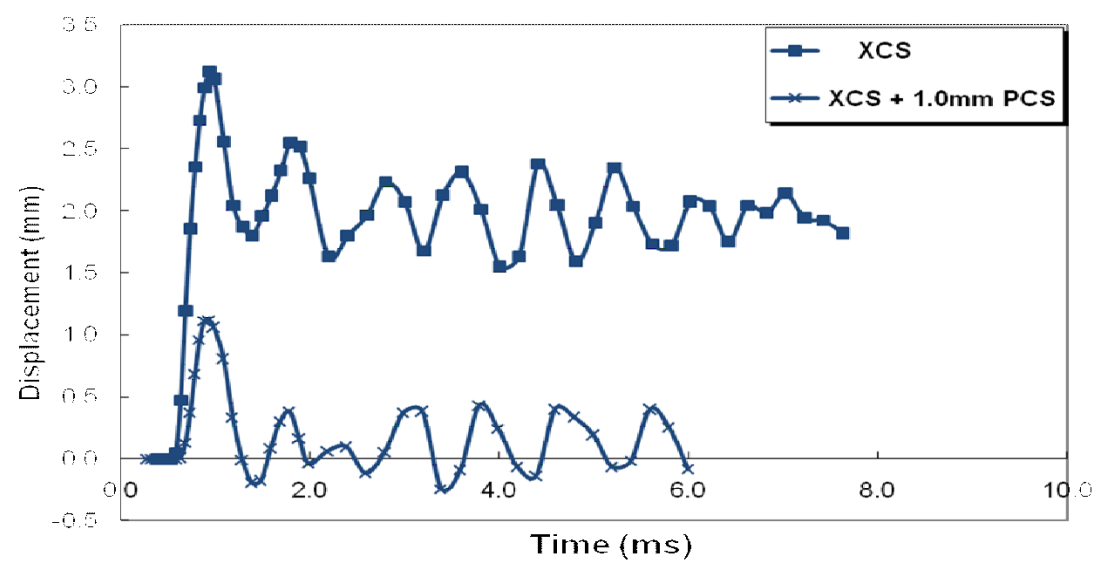

Fig. 18: Displacement-time history at point (2) of armoured door for two cases (2 kg TNT) 


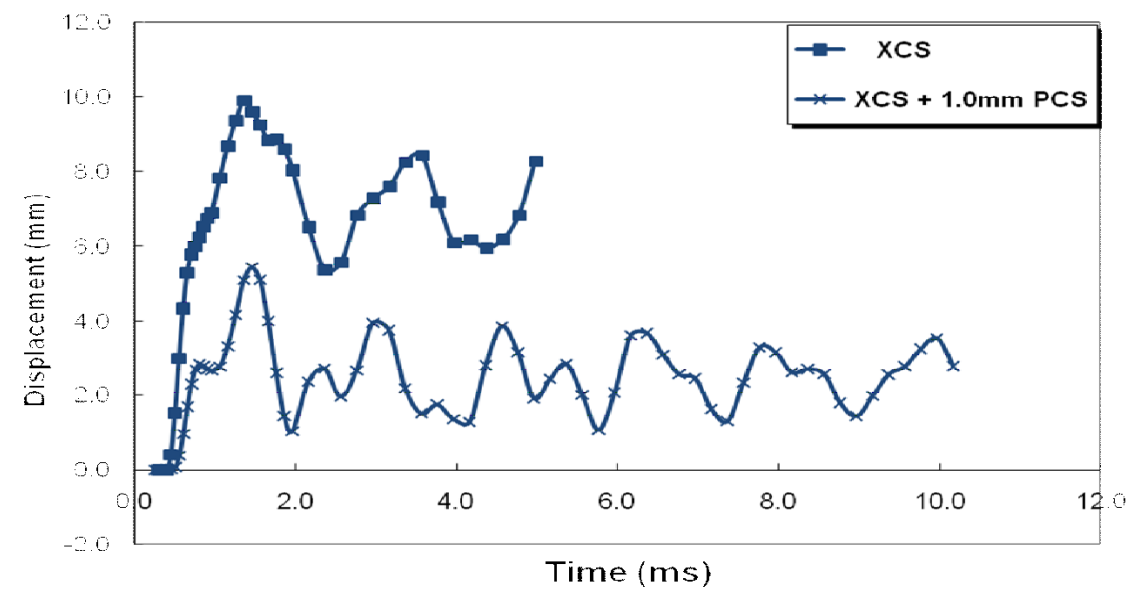

Fig. 19: Displacement-time history at point (1) of armoured XCS door for two cases (3 kg TNT)

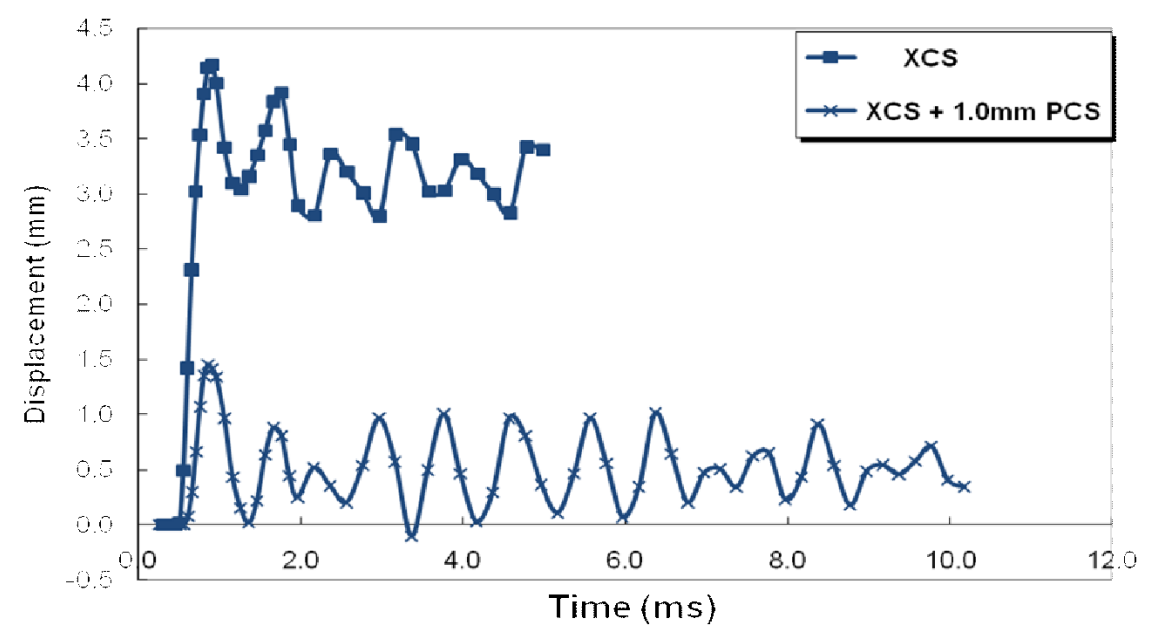

Fig. 20: Displacement-time history at point (2) of armoured XCS door for two cases (3 kg TNT) 